\title{
Time for change: women leading in cardiothoracic surgery, a global perspective
}

This series is a collection of invited lectures presented during the symposium on Global perspectives from Women in Cardiothoracic Surgery held at the European Society of Thoracic Surgeons (ESTS) conference in Dublin, Ireland. The session featured perspectives from surgeons from different continents to explore the current situation of women in the field of cardiothoracic surgeons across the world. The event marked the first in its history where the ESTS held a session focused on Women in Thoracic Surgery. In doing so, it provided all ESTS members and non-members guests the opportunity to network with colleagues from all over the world, sharing work, personal experiences and challenges. The session was considered a resounding success by all attendees serving as a catalyst for this journal series.

In special series of the Fournal of Thoracic Disease we offer a sampling of topics presented during the ESTS session which have been shaped around comments and feedback we received.

Due to the heterogeneity of training paradigms throughout the world, health care systems and cultural backgrounds, were not conceptually easy to describe in a unified manner. Thus, the authors take into account nuanced differences and yet highlight commonalities where they exist in describing the pathways and obstacles that junior female thoracic surgeons are experiencing. With this series we wanted to expand on the success of the ESTS session and share this collection of global experiences by providing our colleagues a mentoring and educational resource.

We present experiences of female thoracic surgeons from Europe, US, Asia and Africa. We also had the honor to have the contributions from experts like Dr. Douglas Wood (past president of the Society of Thoracic Surgeons) who are pioneering initiatives to support female thoracic surgeons. Leaders in medical devices companies have also shared similar challenges and opportunities they have faced during their careers and further highlight opportunities for collaboration. What the Women in Thoracic Surgery has achieved in the US has provided a unique platform for mentorship, leadership and support for women in surgery, and we are pleased to have their leadership contributing to this series.

The past and more recent history have shown that women's rights organisations and movements are important catalysts for gender equality and the realisation of women in professional and personal settings.

It was a pleasure and privilege for the two of us to act as co-editors of this series, representing an extension of the ESTS and Women in Thoracic Surgery collaborative effort dedicated to encouraging, enabling and inspiring women to fulfil their career ambitions. We hope that the information collected in the present series will be a comprehensive collection of experiences and examples which may inspire the current and future generations of thoracic surgeons. We are deeply indebted to all the authors, who contributed to the realization of the present volume. This series is dedicated to all women working in the field of thoracic surgery, surgeons, nurses, physiotherapists and allied health professionals who, with their daily commitment and devotion help promote and advance our specialty and to their partners in work and life for the support and help they provided.

\section{Acknowledgments}

Funding: None.

\section{Footnote}

Provenance and Peer Review: This article was commissioned by the editorial office, fournal of Thoracic Disease for the series "Women in Thoracic Surgery". The article did not undergo external peer review.

Conflicts of Interest: Both authors have completed the ICMJE uniform disclosure form, (available at http://dx.doi.org/10.21037/ jtd-2020-wts-01). The series "Women in Thoracic Surgery" was commissioned by the editorial office without any funding sponsorship. LB and CP served as the unpaid Guest Editors of the series. CP serves as an unpaid editorial board member of 
Fournal of Thoracic Disease from Sep 2020 to Aug 2022. LB reports to have served as a paid speaker consultant for Ethicon (Johnson \& Johnson).

Ethical Statement: The authors are accountable for all aspects of the work in ensuring that questions related to the accuracy or integrity of any part of the work are appropriately investigated and resolved.

Open Access Statement: This is an Open Access article distributed in accordance with the Creative Commons AttributionNonCommercial-NoDerivs 4.0 International License (CC BY-NC-ND 4.0), which permits the non-commercial replication and distribution of the article with the strict proviso that no changes or edits are made and the original work is properly cited (including links to both the formal publication through the relevant DOI and the license). See: https://creativecommons.org/ licenses/by-nc-nd/4.0/.

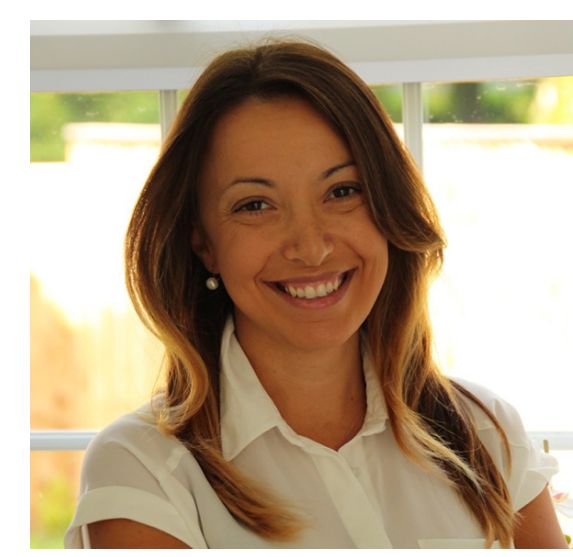

Cecilia Pompili

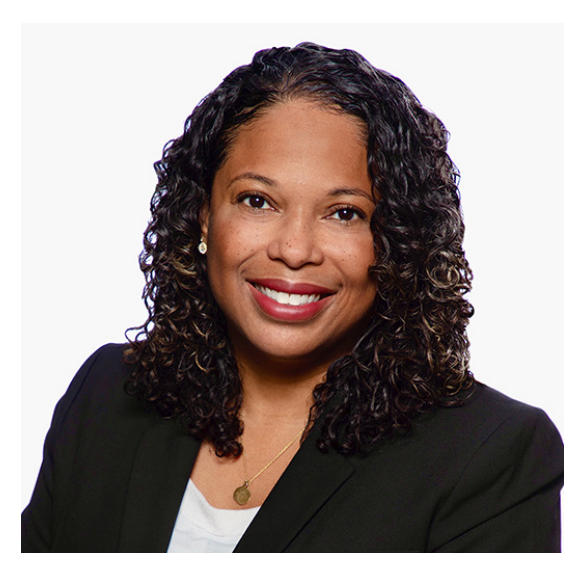

Leah Backhus

Cecilia Pompili ${ }^{1,2}$, MD, PhD

${ }^{1}$ Section of Patient Centred Outcomes Research, Leeds Institute for Medical Research at St fames's, University of Leeds, Leeds, UK;

${ }^{2}$ Thoracic Surgery Department, St fames' Institute of Oncology, Leeds, UK. (Email: C.Pompili@leeds.ac.uk)

Leah Backhus ${ }^{3}$, MD, MPH, FACS

${ }^{3}$ Associate Professor, Division of Thoracic Surgery, Department of Cardiothoracic Surgery, Stanford University, Stanford, CA, USA. (Email: lbackbus@stanford.edu)

Submitted Jun 18, 2020. Accepted for publication Oct 27, 2020.

doi: $10.21037 /$ jtd-2020-wts-01

View this article at: http://dx.doi.org/10.21037/jtd-2020-wts-01

Cite this article as: Pompili C, Backhus L. Time for change: women leading in cardiothoracic surgery, a global perspective. J Thorac Dis 2021;13(1):430-431. doi: 10.21037/jtd-2020-wts-01 